American J. of Engineering and Applied Sciences 2 (1):176-183, 2009

ISSN 1941-7020

(C) 2009 Science Publications

\title{
Optimal Bidding Strategies for a Small Generation Company in a Day-Ahead Electricity Market with Bilateral Contracts Taken into Account
}

\author{
${ }^{1}$ Azmi Saleh, ${ }^{2}$ Takao Tsuji and ${ }^{2}$ Tsutomu Oyama \\ ${ }^{1}$ Department of Electrical Engineering, Jember University, \\ Jl. Slamet Riyadi 62 Jember 68111, Indonesia \\ ${ }^{2}$ Department of Electrical and Computer Engineering, Yokohama National University, \\ 79-5 Tokiwa-dai, Hodogaya-ku, Yokohama 240-8501, Japan
}

\begin{abstract}
Problem Statement: Deregulation power systems have been force to change their structures, from vertically integrated to open market systems. Each generation company (Genco) is required to compete with rivals through bidding in a pool market and making a bilateral contract with a distribution company (Disco) or consumers to maximize its own profits. A unit commitment becomes responsible for each Genco and difficult for Genco that have one generation plant or small generation capacity. The objective of a Genco is to maximize its profits with makes a decision submit bidding price function to the Independent System Operator (ISO). In order to achieve this goal, it is necessary and important for a small Genco to build optimal bidding strategies considering a bilateral contract and a unit commitment with constraints in time periods for possibilities to get a discontinuous dispatch that could reduce total profits. Approach: The proposed methodology employs an optimization method like Lagrange Relaxation to solve the optimal bidding problem. The solution procedure is applied in the study case and change the market condition to show the effect of bilateral contract to marginal clearing price (MCP), generation output and total profit for a small Genco. Result: The result of the proposed method shows that a Genco can build optimal bidding strategies to maximize total profit considering unit commitment and bilateral contract. Simulation results of a numerical example have demonstrated the bilateral contract reduced the hourly MCP. The bilateral contract will guarantee the Genco getting continuous dispatch during time periods. Conclusions/Recommendations: The proposed method for building optimal bidding strategies in a day-ahead electricity market to maximize total profit considering unit commitment and bilateral contract is helpful for a Genco to make decision in submit bidding to an ISO.
\end{abstract}

Key words: Electricity market, bidding strategies, day-ahead electricity market, unit commitment, bilateral contract

\section{INTRODUCTION}

Deregulation and reforms in the electricity market have created a competitive open market environment. Under the deregulated environment, there are two main market structures, a pool-based model and a bilateral contract-based model. Each generation company (Genco) is required to compete with rivals through bidding in a pool market and making a bilateral contract with a distribution company (Disco) or consumers to maximize its own profits.

In a pool-based market, each Genco send bids to the system administrator for each hour. These bids represent the prices at which a Genco is willing to sell power from a specific time period, usually the next 24 hours. The ISO dispatches Gencos in order of lowest to a highest bid as needed to meet forecasted demand. The bid price of the last Genco dispatched during any given hour sets the Market Clearing Price (MCP) for that hour. All Genco dispatched during that hour receive the same MCP regardless of the Genco bid price.

In a bilateral contract market, the Genco and Disco or consumers could negotiate trading quantity (MW), trading price $\left(\$ \mathrm{MWh}^{-1}\right)$ and trading duration (hour) directly with little intervention from ISO. The ISO is responsible for guaranteeing nondiscriminatory access to transmission. The bilateral contract is signed before the actual trading period between Genco and Disco.

A unit commitment becomes responsible for each Genco and difficult for Genco that have one generation

Corresponding Author: Azmi Saleh, Department of Electrical and Computer Engineering, Yokohama National University, 79-5 Tokiwa-dai, Hodogaya-ku, Yokohama 240-8501, Japan 
plant or small generation capacity. In order to build optimal bidding strategies, a Genco should consider a bilateral contract and a unit commitment with constraints in time periods (for example minimum up and down time, start-up and shut-down costs) for possibilities to getting discontinuous dispatch that could reduce total profits.

The problem of how to develop optimal bidding strategies for competitive Genco in the electricity market was addressed for the first time $\mathrm{in}^{[1]}$, and a conceptual optimal bidding model and a dynamicprogramming based approach was develop. The strategic bidding models based on estimating the Market Clearing Price (MCP) is developed for competitive electricity market $\mathrm{in}^{[2,3]}$. The bidding problem was modeled as bi-level problem by assuming complete information and probabilistic estimates on a Genco's opponents is presented in ${ }^{[4,5]}$. The Genco determine its bidding strategies by offering in a price cheaper than the MCP. The developing bidding strategies based on game theory to simulate the bidding behaviors of Gencos and develop Nash equilibrium bidding strategies is presented $\mathrm{in}^{[6-7]}$. The bidding strategy using Markov Decision Process (MDP) was applied to derive the studied Gencos bidding decision is presented in ${ }^{[8]}$. The bidding strategy using a Fuzzy-CMean (FCM) algorithm and the Artificial Neural Network (ANN) is developed for competitive electricity market $\mathrm{in}^{[9]}$. The bidding strategy with optimally coordinated energy and spinning reserve market is presented $\mathrm{in}^{[10]}$. All above mentioned researches, dealing with optimal bidding in electricity market without considering unit commitment and bilateral contract.

In this tsudy the problem of building optimal bidding strategies off small Genco is proposed where both unit commitment and bilateral contract are taken into account. The numerical test result of a simulated electricity market with four Gencos used to demonstrate the effect of trading quantity on MCP, generation output and unit commitment constraint in small Genco.

\section{MATERIAL AND METHODS}

Market Structure: In the pool-based electricity market, every Genco submits bidding price function to the Independent System Operator (ISO) for every hour of the planning horizon. The ISO uses bidding price function and forecasting demand to determine Market Clearing Price (MCP) and hourly generation outputs by maximizing the total surplus of generators and consumers. Assume that each Genco is required to submit linear bidding price function $B_{j}\left(P_{j}\right)=\alpha_{j}+\beta_{j} P_{j}$, where $P_{j}$ is the generation output and $\alpha_{j}$ and $\beta_{j}$ are bidding coefficient of bidding price function. The ISO determine the MCP and hourly generation outputs each Genco using formulation as:

$R=\left[Q_{0}+\sum_{j=1}^{n} \frac{\alpha_{j}}{\beta_{j}}\right] /\left[\sum_{j=1}^{n} \frac{1}{\beta_{j}}\right]$

$P_{j}=\frac{R-\alpha_{j}}{\beta_{j}}$

Subject to:

$\sum_{j=1}^{N} P_{j}=Q$

$\mathrm{P}_{\mathrm{j}, \min } \leq \mathrm{P}_{\mathrm{j}} \leq \mathrm{P}_{\mathrm{j}, \max }$

Where:

$\mathrm{R}=$ The marginal clearing price

$\mathrm{Q}=$ The pool load forecasted

$P_{j}=$ The generation output jth Genco

The profit function of jth Genco is defined by the difference between the total revenue and the total production cost as:

$\pi_{\mathrm{j}}=\mathrm{R} \cdot \mathrm{P}_{\mathrm{j}}-\mathrm{C}\left(\mathrm{P}_{\mathrm{j}}\right)$

Subject to: (3)-(4)

Where, $\mathrm{C}_{\mathrm{j}}($.$) is the production cost function of the$ jth Genco.

If the jth Genco have bilataral contract with Disco or consumers, where the quantities traded is $\mathrm{Pb}(\mathrm{MW})$ and the price traded is $\mathrm{Rb}(\$ / \mathrm{MWh})$. The profit function of jth Genco is modified as:

$\pi_{j}=R \cdot P_{j}+R_{b} \cdot P_{b}-C\left(P_{j}+P_{b}\right)$

The problem of building optimal bidding strategies for the jth Genco is determining bidding coefficient $\left(\alpha_{j}\right.$ and $\beta_{\mathrm{j}}$ ) so as to maximize profit subject to constraints (3)-(4).

Optimal Bidding Strategies in a day-ahead Electricity Market: The problem of developing bidding strategies for ith Genco in a day-ahead electricity market can be formulated as:

$\max \Omega=\sum_{\mathrm{t}=1}^{24}\left[\mathrm{u}_{\mathrm{t}} \cdot \pi_{\mathrm{i}}^{(\mathrm{t})}-\mathrm{ST}_{\mathrm{i}}^{(\mathrm{t})} \mathrm{u}_{\mathrm{t}}\left(1-\mathrm{u}_{\mathrm{t}-1}\right)\right]$ 
Subject to:

$$
u_{t}= \begin{cases}1 & \text {, if } T_{\text {on }}>T_{\text {up }} \\ 0 & \text { if } \mathrm{T}_{\text {off }}>\mathrm{T}_{\text {down }} \\ 0 \text { or } 1, & \text { otherwise }\end{cases}
$$

Where:

$$
\begin{array}{ll}
\mathrm{ST} & =\text { The start-up cost, } \\
\mathrm{u}_{\mathrm{t}} & =\text { The status of the ith Genco (1: operation, } 0: \\
& \text { down) } \\
\mathrm{T}_{\text {on }} & =\text { On time duration of the ith Genco. } \\
\mathrm{T}_{\text {off }} & =\text { Off time duration of the ith Genco. } \\
\mathrm{T}_{\text {up }} & =\text { Minimum up time } \\
\mathrm{T}_{\text {down }} & =\text { Minimum down time. }
\end{array}
$$

When an ith Genco is in operation, it cannot shut down before a minimum up time period is met. On the other hand, when an ith Genco is in shut down, it cannot start up again before a minimum down time have passed. If minimum up time and minimum down time period have passed, the status of the ith Genco can set to 1 or 0 as to maximize total profit.

To solve Eq. 7 directly is difficult and should be solved separately as follow:

- Step 1: Developing the bidding strategies and the status (ut) of the ith Genco for each hour of the schedule day, separately, using Eq. 6. If the ith Genco gets dispatch from ISO, set value of ut to 1 , otherwise, set to 0 (zero).

- Step 2: Checking the status of the ith Genco with the unit commitment constraint. If the unit commitment constraint is satisfied, then these strategies are optimal for a day-ahead market and the ith Genco should remain in operation for the whole day and the procedure is completed here. Otherwise, go ahead to step 3 to update status for ith Genco.

- Step 3: Determining the status for ith Genco to satisfy the unit commitment constraint using dynamic programming to maximize total profit during 24 hours. If ith Genco should be in operation because of the commitment constraint (due to constraints of minimum up time), update bidding coefficients and reduce bidding offer so that ith Genco can obtain dispatch from ISO.

The dynamic programming represents a multi stage decision problem as a sequence of single decision problems. The advantage of dynamic programming is its ability to maintain solution feasibility, unlike priority list method. Dynamic programming builds and evaluates the complete decision tree to optimize the problem.

The two possible states for ith Genco $\left(u_{t}=0\right.$ or 1$)$ problem can be solved using forward dynamic programming algorithm to run forward in time from initial hour to the final hour. The initial conditions are easily specified and the computations can go forward in time since required.

Solution Procedure: In order to solve the problem of building optimal bidding strategies for ith Genco in a day-ahead electricity market, first the ith Genco building optimal bidding strategies for each hour that maximize hourly profit using Eq. 5 or using Eq. 6 if ith Genco have a bilateral contract with consumers. Equation 5 or 6 as objective function and Eq. 3-5 as constraints can be solved using optimization method such as lagrangian relaxation.

The problem of building the optimal bidding strategies for ith Genco as Eq. 7 could be expressed as:

$\max \pi_{\mathrm{i}}\left(\alpha_{\mathrm{i}}, \beta_{\mathrm{i}}, \mathrm{P}_{\mathrm{i}}\right)=\left(\mathrm{R}_{\mathrm{b}} \mathrm{P}_{\mathrm{b}}+\left(\alpha_{\mathrm{i}}+\beta_{\mathrm{i}} \cdot \mathrm{P}_{\mathrm{i}}\right) \mathrm{P}_{\mathrm{i}}\right)-\mathrm{C}_{\mathrm{i}}\left(\mathrm{P}_{\mathrm{i}}+\mathrm{P}_{\mathrm{b}}\right)$

Subject to: (3)-(6)

Denote $\mathrm{u}=\mathrm{Q}_{0}+\sum_{\mathrm{j} \neq \mathrm{i}} \frac{\alpha_{\mathrm{j}}}{\beta_{\mathrm{j}}}$ and $\mathrm{v}=\sum_{\mathrm{j} \neq \mathrm{i}} \frac{1}{\beta_{\mathrm{j}}}$. Equation 4 and 5 could be expressed as:

$\mathrm{R}=\frac{\alpha_{\mathrm{i}}+\mathrm{u} \beta_{\mathrm{i}}}{\mathrm{v} \beta_{\mathrm{i}}+1}$

$P_{i}=\frac{u-\alpha_{1} v}{v \beta_{i}+1}$

Equation 9 could be solved through the generalized Lagrange multiplier method as:

$$
\begin{aligned}
\mathrm{L}\left(\alpha_{\mathrm{i}}, \beta_{\mathrm{i}}, \mathrm{P}_{\mathrm{i}}, \lambda\right)= & \mathrm{R}_{\mathrm{b}} \cdot \mathrm{P}_{\mathrm{b}}+\left(\alpha_{\mathrm{i}}+\beta_{\mathrm{i}} \cdot \mathrm{P}_{\mathrm{i}}\right) \mathrm{P}_{\mathrm{i}}-\mathrm{C}_{\mathrm{i}}\left(\mathrm{P}_{\mathrm{i}}+\mathrm{P}_{\mathrm{b}}\right) \\
& +\lambda\left(\mathrm{u}-\alpha_{\mathrm{i}} \mathrm{v}-\mathrm{P}_{\mathrm{i}}\left(\mathrm{v} \beta_{\mathrm{i}}+1\right)\right)
\end{aligned}
$$

The optimal solution of Eq. 14 with applying Kuhn=Tucker conditions, could be obtained assuming $\alpha_{i}=b_{i}$ are:

$\beta_{i}=\frac{\left(2 c_{i} v+1\right) b_{i}-2 c_{i} P_{b}-2 c_{i} u-u / v}{v b_{i}+2 c_{i} P_{b}-u}$

Subject to: 
Am. J. Engg. \& Applied Sci., 2 (1):176-183, 2009

$$
\mathrm{P}_{\mathrm{i}, \min } \leq \mathrm{P}_{\mathrm{i}} \leq \mathrm{P}_{\mathrm{i}, \max }
$$

When $\mathrm{P}_{\mathrm{i}}$ is less than $\mathrm{P}_{\mathrm{i}, \mathrm{min}}$, update $\beta_{\mathrm{i}}$ using formula as:

$$
\beta_{i}=\frac{u-b_{i} v-P_{i, \min }}{v \cdot P_{i, \min }}
$$

When $P_{i}$ is greater than $P_{i, \max }$, update $\beta_{i}$ using formula (14) with replace $P_{i, \text { min }}$ with $P_{i, \max }$.

\section{RESULTS}

In the simulations, four Gencos is assumed to participate in the electricity market. Assume each Genco have one generation unit with a quadratic production cost curve. The quadratic production cost curve data and output are shown in Table 1.

Two cases are considered:

- The electricity market only have one market structure (pool-based model)

- The electricity market have two market structure (pool-based model and bilateral contract based model)

The forecasted load for a day-ahead electricity market that ISO broadcast is shown in Fig. 1.

Perfect market competition: The ideal market is a perfect competitive market in which Gencos bid their marginal cost $\partial \mathrm{C}\left(\mathrm{P}_{\mathrm{j}}\right) / \partial \mathrm{P}_{\mathrm{j}}=\mathrm{b}_{\mathrm{j}}+2 \mathrm{c}_{\mathrm{j}} \mathrm{P}_{\mathrm{j}}$ as shown in Fig. 2. In this market, it is assumed no Gencos have the capability to influencing the prices. The effect of bilateral contract on MCP, generation output and unit commitment constraint in small Genco (fourth Genco) analyze in perfect market competition.

In the bilateral contract market, the trading quantity (MW), trading price (\$/MWh) and trading duration (hour) between Genco and consumers are shown in Table 2.

In this simulation, the effect of trading quantity on MCP, generation output and unit commitment constraint in small Genco (fourth Genco) also analyze. In second case, it is assumed fourth Genco have different trading quantity $5 \mathrm{MW}, 10 \mathrm{MW}$ and $15 \mathrm{MW}$, respectively.

The marginal clearing price and generation output every Genco in two cases could achieve by solving Eq. 1-2. The results are shown in Fig. 3, 4 and 5.
Table 1: Data of gencos

\begin{tabular}{lrrlll}
\hline Genco & $\mathrm{a}$ & $\mathrm{b}$ & $\mathrm{c}$ & $\mathrm{Pmin}(\mathrm{MW})$ & Pmax (MW) \\
\hline 1 & 94 & 9.4 & 0.0094 & 50 & 250 \\
2 & 96 & 9.6 & 0.0096 & 50 & 250 \\
3 & 105 & 10.0 & 0.0100 & 50 & 250 \\
4 & 30 & 11.0 & 0.0110 & 10 & 50 \\
\hline
\end{tabular}

Table 2: Data of bilateral contract market

\begin{tabular}{llll}
\hline Genco & $\mathrm{Pb}(\mathrm{MW})$ & $\mathrm{Rb}(\$ / \mathrm{MWh})$ & $\mathrm{T}($ hour $)$ \\
\hline 2 & 15 & 12.5 & 24 hours \\
3 & 15 & 12.5 & 24 hours \\
4 & 5,10 or 15 & 12.5 & 24 hours \\
\hline
\end{tabular}

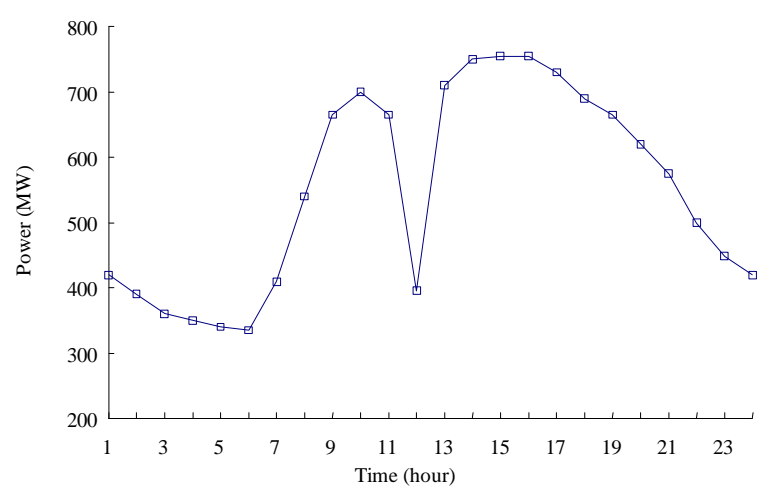

Fig. 1: Hourly Loads

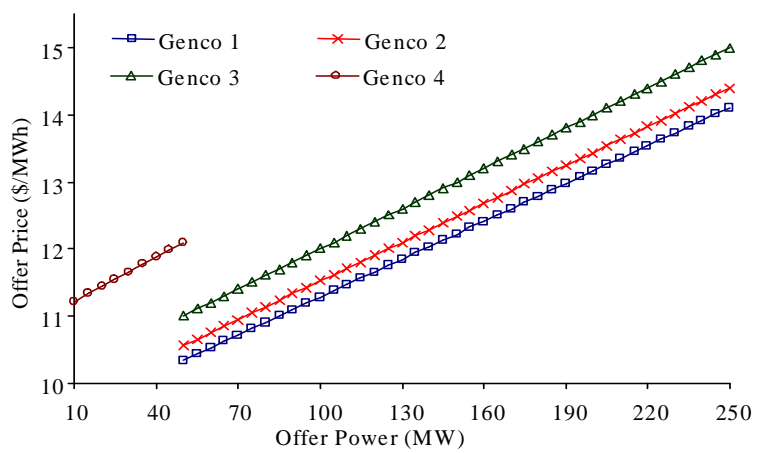

Fig. 2: The gencos offer curves

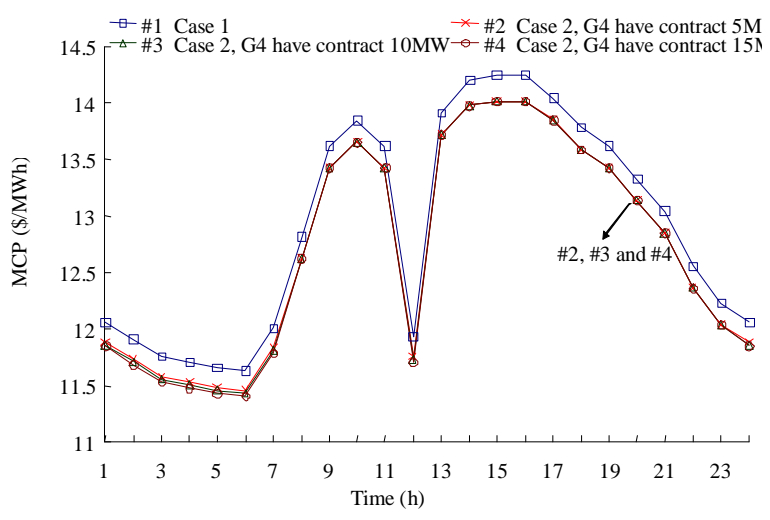

Fig. 3: Hourly MCP 


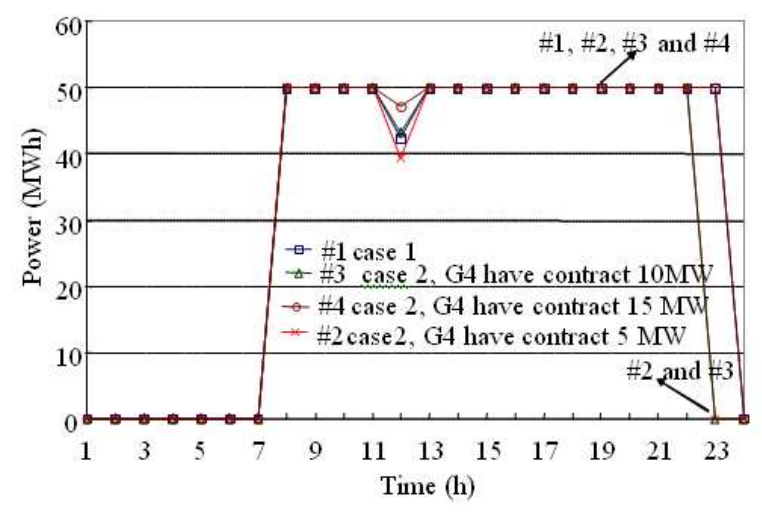

Fig. 4: Generation Output for Genco 4

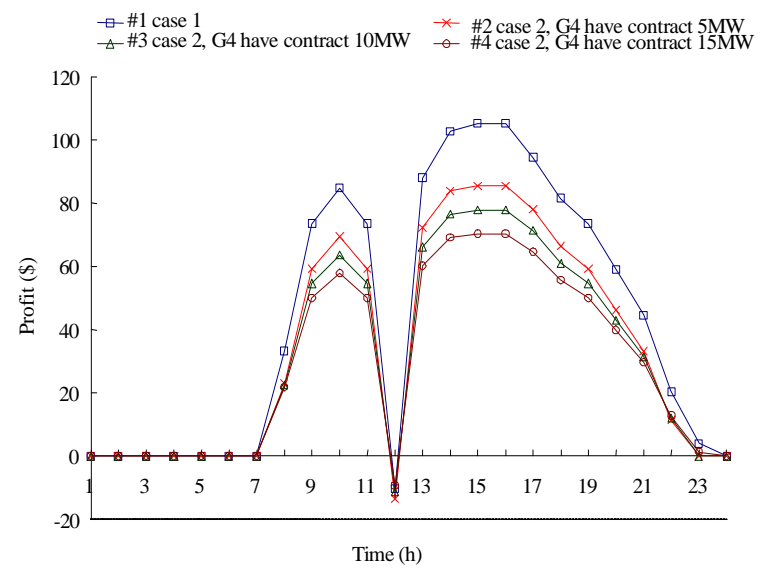

Fig. 5: Hourly Profit for Genco 4

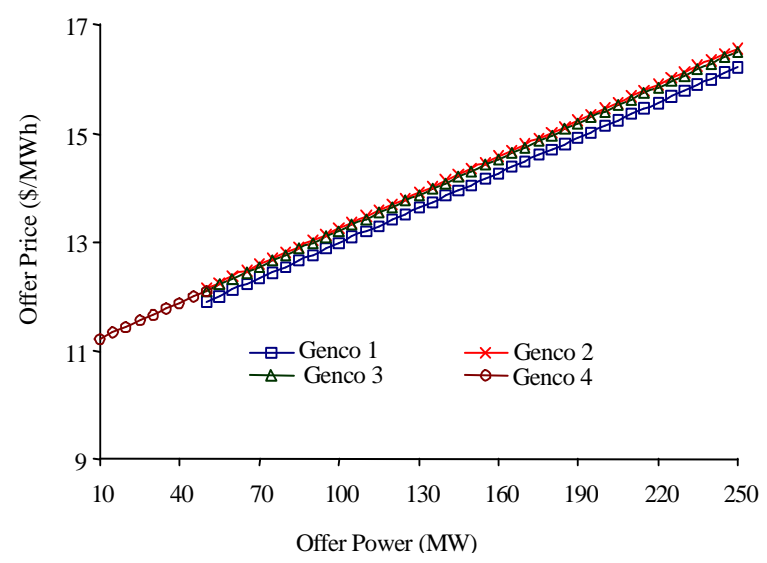

Fig. 6: The Gencos Offer Curves

Imperfect Market Competition: In the imperfect market competition, the Genco could increase bidding at higher than marginal cost to maximize its own profit. Assume the Genco 1 and 2 increase bid $15 \%$ than marginal cost and the Genco 3 increase bid 10\% than marginal cost. The Genco 4 still bid their marginal cost. Gencos offer curves shown in Fig. 6.

The bilateral contract market assumed same as perfect market competition except the trading price is change to $14 \$ / M W h$. The trading price change to $14 \$ / \mathrm{MWh}$ because the MCP average in imperfect market competition is $14.4 \$ / \mathrm{MWh}$. If trading price too low, no Genco will make bilateral contract with consumer. The hourly MCP, generation output and hourly profit for Genco 4 are shown in Fig. 7, 8 and 9.

Optimal Bidding Strategy in Imperfect Market Competition: In the imperfect market competition, the Genco 4 increase bid using optimal bidding strategy beside the Genco 1 and 2 increase bid $15 \%$ than marginal cost and the Genco 3 increase bid 10\% than marginal cost. With assuming the bidding coefficient (intercept) for Genco 4 is $\alpha_{4}=b_{4}$, the optimal bidding coefficient (slope) for Genco 4 is shown in Table 3.

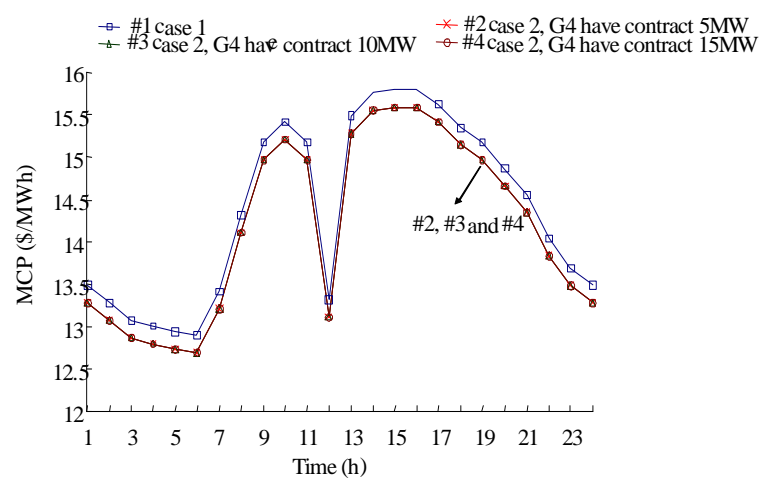

Fig. 7: Hourly MCP

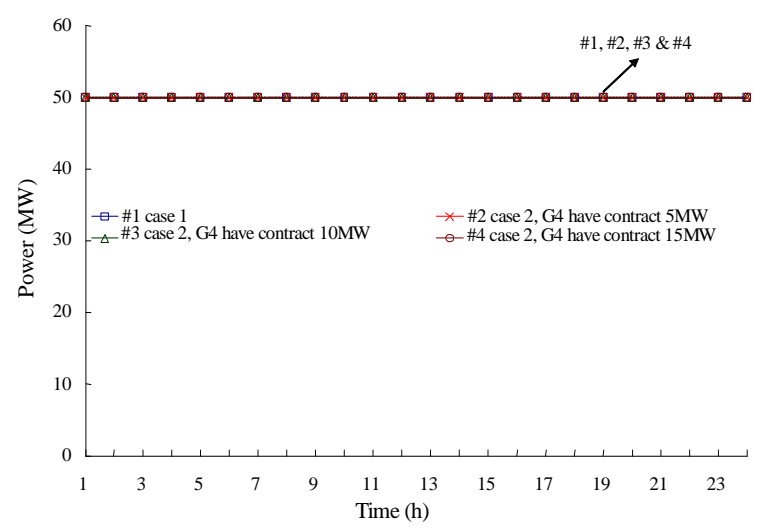

Fig. 8: Generation Output for Genco 4 


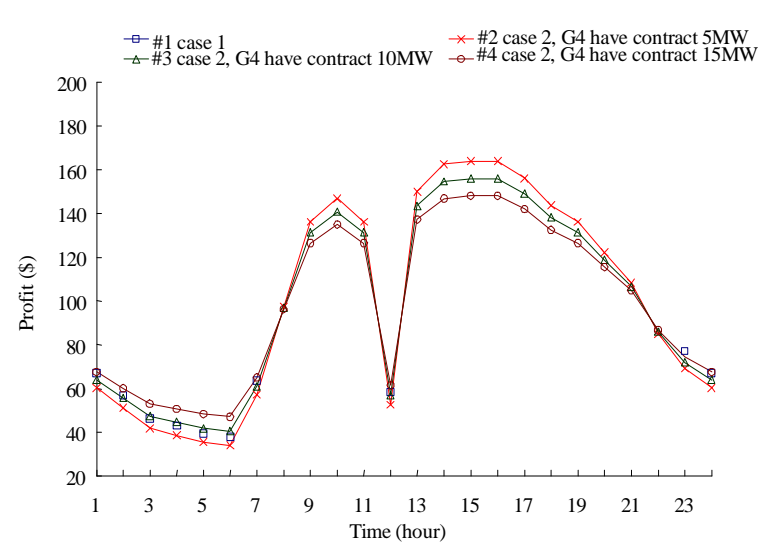

Fig. 9: Hourly Profit for Genco 4

Table 3: Optimal Bidding Coefficients for Fourth Genco

\begin{tabular}{llll}
\hline $\mathrm{T}$ & $\begin{array}{l}\beta_{\mathrm{I}} \\
(\text { Case 1) }\end{array}$ & $\begin{array}{l}\beta_{\mathrm{I}} \text { (Case 2, with } \\
\text { contract 5MW) }\end{array}$ & $\begin{array}{l}\beta_{\mathrm{I}}(\text { Case 2, with } \\
\text { contract 15MW) }\end{array}$ \\
\hline 1 & 0.0498 & 0.0508 & 0.0653 \\
2 & 0.0457 & 0.0462 & 0.0594 \\
3 & 0.0416 & 0.0416 & 0.0535 \\
4 & 0.0402 & 0.0401 & 0.0515 \\
5 & 0.0388 & 0.0386 & 0.0496 \\
6 & 0.0381 & 0.0378 & 0.0486 \\
7 & 0.0484 & 0.0492 & 0.0633 \\
8 & 0.0663 & 0.0691 & 0.0888 \\
9 & 0.0835 & 0.0882 & 0.1134 \\
10 & 0.0883 & 0.0935 & 0.1202 \\
11 & 0.0835 & 0.0882 & 0.1134 \\
12 & 0.0464 & 0.0470 & 0.0604 \\
13 & 0.0897 & 0.0950 & 0.1222 \\
14 & 0.0952 & 0.1012 & 0.1301 \\
15 & 0.0958 & 0.1019 & 0.1310 \\
16 & 0.0958 & 0.1019 & 0.1310 \\
17 & 0.0924 & 0.0981 & 0.1261 \\
18 & 0.0869 & 0.0920 & 0.1183 \\
19 & 0.0835 & 0.0882 & 0.1134 \\
20 & 0.0773 & 0.0813 & 0.1045 \\
21 & 0.0711 & 0.0744 & 0.0957 \\
22 & 0.0608 & 0.0630 & 0.0810 \\
23 & 0.0538 & 0.0552 & 0.0710 \\
24 & 0.0498 & 0.0508 & 0.0653 \\
\hline
\end{tabular}

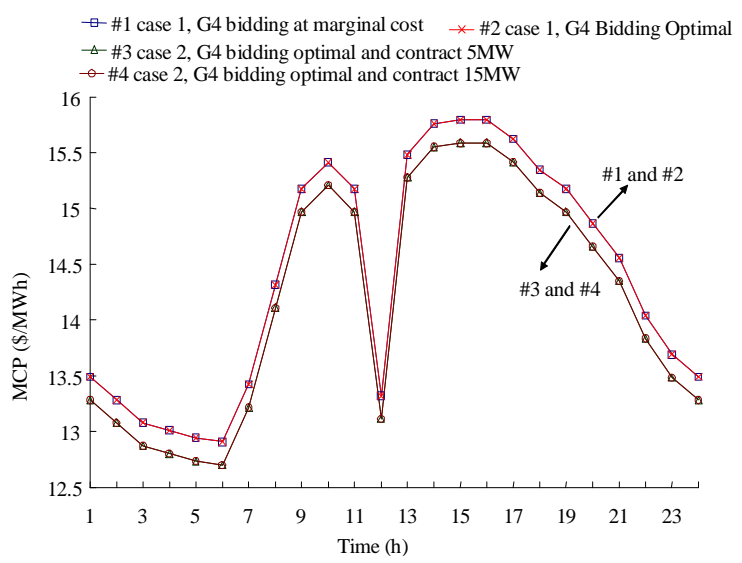

Fig. 10: Hourly MCP

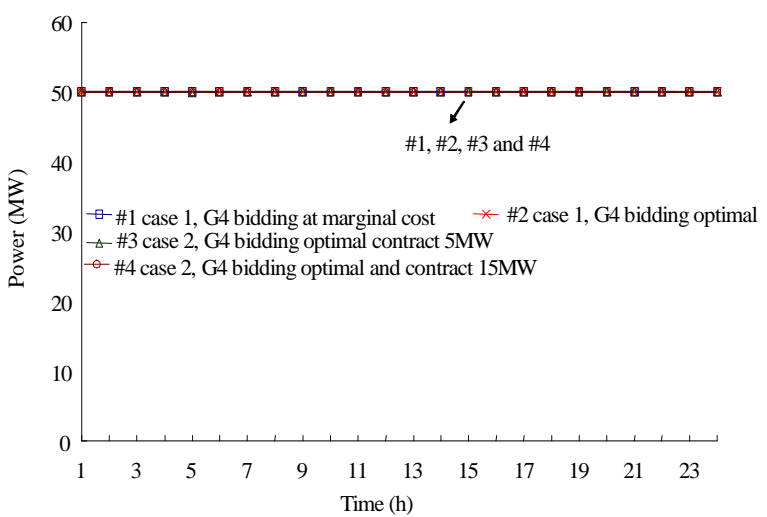

Fig. 11: Generation Output for Genco 4

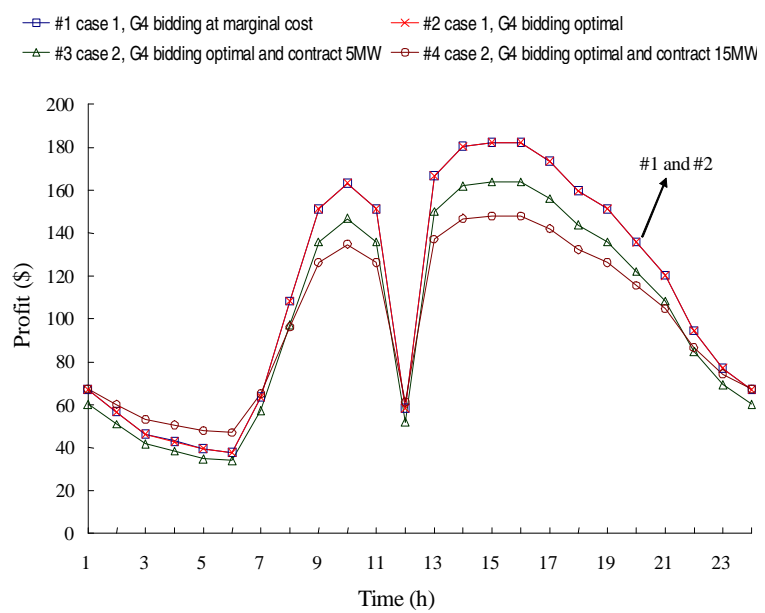

Fig. 12: Hourly Profit for Genco 4

Table 3 shown the effect of bilateral contract to bidding coefficient for Genco 4. The fourth Genco increased bidding price if Genco 4 have bilateral contract. The traiding quantity of bilateral contract increasing, the bidding price also increasing. In this condition, increasing the bidding price could not change hourly MCP as shown in Fig. 10. The generation output and profit for Genco 4 are shown in Fig. 11 and 12, respectively.

\section{DISCUSSION}

Perfect market competition: It is observed from Fig. 3 , that MCP is lower in case 2 than case 1 . The change of trading quantity of Genco 4 did not effect to MCP as shown in graph of case 2 with Genco 4 have bilateral contract 5MW, 10MW and 15MW, respectively. The effect of bilateral contract will reduce the hourly MCP.

Figure 4 shows the effect of bilateral contract to generation level for Genco 4. The Genco 4 getting 
negative profit during hour 1-7, hour 12 and hour 23-24 in case 2 with trading quantity $5 \mathrm{MW}$ and $10 \mathrm{MW}$ because the MCP small and did not cover the fixed cost operation with low generation output. However, the Genco 4 getting positive profit in hour 23 in case 1 and in case 2 with trading quantity $15 \mathrm{MW}$. This is because the MCP in case 1 higher than case 2 . The profit in case 2 with trading quantity $15 \mathrm{MW}$ is positive because revenue from pool-based and bilateral contract higer than production cost.

The Genco 4 getting a discontinue dispatch and unit constraint did not satisfy. The Genco 4 determined the unit commitment status using dynamic programming to make unit commitment constraint is satisfy with assuming initial condition for Genco 4 is off. Final result is from the commitment status is still submit offer in hour 12 with negative profit.

Figure 5 show the effect of bilateral contract to profit for Genco 4. In general, comparing the profit bentween case 1 and case 2 is decrease, especially during hour 9-11 and 14-20. By increasing the trading quantity, the profit decreases. The different price between MCP and contract price during hour 9-11 and 14-20 is high. It means the trading price did not reasonably comparing with trading quantity. The fourth Genco should evaluate the quantity and price in making bilateral contract with costumer comparing with MCP in pool-based market. The total profit in case 1 and 2 (with trading quantity $5 \mathrm{MW}$, $10 \mathrm{MW}$ and 15MW) are \$1033.6, \$819.0, 756.0 and 694.0, respectively.

Imperfect Market Competition: It is observed from Fig. 7, the MCP is lower in case 2 than case 1. The change trading quantity of Genco 4 did not effect to MCP as show in graph of case 2 with Genco 4 have bilateral contract $5 \mathrm{MW}, 10 \mathrm{MW}$ and $15 \mathrm{MW}$, respectively. The effect of bilateral contract will reduce the hourly MCP.

In Fig. 8 shown the effect of bilateral contract to generation output for Genco 4. The Genco 4 getting continuous dispatch at all case, because MCP is higher than bidding price of Genco 4 . The effect of bilateral did shown because the Genco bidding to low comparing with the MCP.

Figure 9 shown the effect of bilateral contract to profit for Genco 4. Comparing the profit in case 1 and case 2 with Genco 4 have contract 10MW and 15MW it increases during hours 1-6. This is because the trading price in bilateral contract is higher than MCP. However, comparing the profit in case 1 and case 2 with Genco 4 have contract 5MW it decrease during hours 1-6 because the trading quantity too small to cover the reduce the MCP. By increasing the trading quantity, the profit during hours 1-6 also increases.
Comparing the profit in case 1 and case 2 it decreases during hours 7-24. This is because the trading price in bilateral contract is lower than MCP. By increasing the trading quantity, the profit during hours 7-24 also decreases. The total profit in case 1 and case 2 (with trading quantity $5 \mathrm{MW}, 10 \mathrm{MW}$ and $15 \mathrm{MW}$ ) are \$2677.05, \$2408.69, \$2387.72 and \$2366.86, respectively.

If the fourth Genco decide to submit bidding at marginal cost, the fourth Genco should evaluate quantity in making bilateral contract with costumer. By increasing the trading quantity, the total profit decreases. In this case, bilateral contract only guarantee the continuous dispatch.

Optimal Bidding Strategy in Imperfect Market Competition: It is observed from Fig. 10, the hourly MCP is same comparing the Genco 4 submit bidding price at marginal cost and submit optimal bidding price. Also, the quantity of bilateral contract could not change hourly MCP even though the Genco 4 increased the bidding price. The effect of bilateral contract will reduce the hourly MCP.

In Fig. 11, the generation output of Genco 4 is same in all case. The Genco did not determine the unit commitment status because getting continuous dispatch in all case.

Figure 12 shown the effect of optimal bidding strategies to the profit for Genco 4. The profit of Genco 4 is same comparing Genco 4 submit bidding price at marginal cost and submit optimal bidding price in case 1. Comparing the profit in case 2 with Genco 4 have contract 5MW and 15MW it increases during hours 1-6. This is because the trading price in bilateral contract is higher than MCP. By increasing the trading quantity, the profit during hours 1-6 also increased.

However, comparing the profit in case 2 with Genco 4 have contract 5MW and $15 \mathrm{MW}$ it decreased during hours 9-11 and hours 13-18. This is because the trading price in bilateral contract is lower than MCP. By increasing the trading quantity, the profit during hours 9-11 and hours 13-18 also decreased. The total profit in case 1 (submit bidding price at marginal cost and at optimal bidding price) and case 2 (submit bidding price optimal bidding price with trading quantity $5 \mathrm{MW}$ and $15 \mathrm{MW}$ ) are $\$ 2677.05, \$ 2677.05$, \$2405.93 and \$2364.72, respectively.

\section{CONCLUSION}

In this stdy, optimal bidding strategy in day-ahead electricity market considering a bilateral contract from the Genco viewpoint is discussed. Simulation results of a numerical example have demonstrated the effect of a bilateral contract will reduce the hourly MCP. The 
bilateral contract will guarantee the Genco getting continuous dispatch during time periods.

In this case study, it is shown the effect of bilateral contract to decision in submit bidding to ISO. However, the Genco should evaluate the quantity and price in making bilateral contract with costumer. The Genco should compare the trading price with MCP in pool base market before decided the quantity of bilateral contract. The quantity of bilateral contract will effect to total profit.

\section{REFERENCES}

1. David, K., 1993. Competitive bidding in electricity supply. IEE Proceedings of the Generation, Transmission and Distribution, Sept. 1993, IEEE Xplore, USA., $\quad$ pp: 421-426. http://ieeexplore.ieee.org/xpl/freeabs_all.jsp?arnum ber $=237910$

2. Shangyou Hao, 2000. A study of basic bidding strategy in clearing pricing auctions. IEEE Trans. Power Syst., 15: 975-980. DOI: 10.1109/59.871721

3. Ferrero, R.W. and J.F. Rivera, 2002. Price-taker bidding strategy under price uncertainty. IEEE Trans. Power Sys., 17: 1081-1088. DOI: 10.1109/TPWRS.2002.804948

4. Weber, J. and T. Overbye, 1999. A Two-level optimization problem for analysis of market bidding strategies. IEEE PES Summer Meet, 2: 682-687. DOI: 10.1109/PESS.1999.787399
5. Gountis, V.P. and A.G. Akirtzis, 2004. Bidding strategies for electricity producers in a competitive electricity marketplace. EEE Trans. Power Sys., 19: 356-365. DOI: 10.1109/TPWRS.2003.821474.

6. Ferrero, R.W. and J.F. Rivera, 2002. Price-taker bidding strategy under price uncertainty. IEEE Trans. Power Syst., 17: 1081-1088. DOI: 10.1109/TPWRS.2003.820703

7. Lia Tao and Shahidehpour Mohammad, 2005. Strategic of transmission constrained gencos with incomplate information. IEEE Trans. Power Sys., 20: 437-447. DOI: 10.1109/TPWRS.2004. 840378

8. Song, H.L. C.C. Liu and J. Lawarree, 2000. Optimal electricity supply bidding by maekov decision process. IEEE Trans. Power Sys., 15: 618-624. DOI: $10.1109 / 59.867150$

9. Hong, Y.Y. S.W. Tsai and T. Weng, 2001. Bidding strategy based on artificial intelligence for a competitive electric market. IEE Proceeding of the Generation, Transmission Distribution, Mar. 2001, IEEE Xplore, USA., pp: 159-163. DOI: 10.1049/ ip-gtd:20010124

10. Soleymani, S. A.M. Ranjbar and A.R. Shirani, 2007. New approach for strategic bidding of gencos in energy and spinning reserve markets. Energ. Conversion Mange., 48: 2044-2052. DOI: 10.1016/j.enconman.2007.01.002 